This is a pre-publication version of the article, accepted for publication in Annals of Tourism Research. Please cite as follows:

Nunkoo R., Hall, C. M., and Ladsawut, J. Gender and Methodology in Tourism social Science Research. Annals of Tourism Research.

\title{
GENDER AND METHODOLOGY IN TOURISM SOCIAL SCIENCE RESEARCH
}

Tourism research has grown remarkably since the early 1980s as manifested in the number and range of publications in this field (Figueroa-Domecq et al., 2015; Li \& Xu, 2014). For example, Hunt, Gao, and Xu (2014) estimate that there are currently more than 240 tourism journals published in different languages. The rise in publication outlets has led to a number of studies on what Figueroa-Domecq et al. (2015, p. 88) called the "scholarship on the scholarship” of tourism knowledge (e.g. Hall, 2011, 2016). However, such research has been criticized for often being 'gender-blind' (Figueroa-Domecq et al., 2015). This is an important research gap because gender has been found to influence research-related issues (Rosser, 2008), such as choice of methodology (Justham \& Timmons, 2005). Oakley (2000) and Justham and Timmons (2005) proposed that women have a preference of qualitative research methods over other types of research approaches.

Therefore this paper investigates authorship patterns and the relationship between gender of authors and methodological approaches used in Annals of Tourism Research (ATR) which, in addition of its international scope and status, is devoted to only publishing articles that are grounded in tourism social science. Full length articles published in ATR from 1990 to 2015 were analyzed with 1990 being used as the starting point because women authors' contributions to tourism journals have been reported as very negligible in earlier years in several studies on academic leadership (e.g. Zhao \& Ritchie, 2007). Each issue of the journal was examined and the following categories were used to classify articles: (1) qualitative: refers to an article based only on qualitative methods of data collection and/or qualitative 
methods of analysis; (2) quantitative: refers to an article based only on quantitative methods of data collection and/or quantitative data analysis techniques; (3) mixed-method: refers to an article based on both qualitative and quantitative approaches; and (4) conceptual: refers to articles with untested theoretical models, hypotheses and/or propositions, and literature review articles. Information was also collected on author gender. The data were coded and analyzed in SPSS.

\section{INSERT TABLE 1 ABOUT HERE}

\section{INSERT FIGURE 1 AND 2 ABOUT HERE}

As presented in Table 1, 1216 articles authored by 2272 individuals were retrieved from ATR from 1990 to 2015. Male authors constituted more than $65 \%$ of all authors in this time period. Nevertheless, while the proportion of male authors with respect to total authors was as high as $80 \%$ in 1990, it fell to around 70\% and 50\% in 2000 and 2015 respectively. The proportion of female authors increased from around $19 \%$ in 1990 to $49 \%$ in 2015 . Figure 1 and 2 show the time series of authorship and types of articles published in the journal between 1990 and 2015. To statistically assess growth of female and male authors in articles published in ATR, linear and quadratic time effects were used. First, the number of female authors on an index of year of publication (beginning with 1990) was regressed. Model estimation using a linear term resulted in a significant model $(F=76.46, p<0.001)$ in which time effect was significant $(t=8.74, p<0.001)$. The model indicated that time could explain $76 \%$ of the presence of female authors. Next, we used both linear and quadratic time effects. The regression model was significant $(F=66.54, p<0.001)$ and indicated that $85 \%$ of the presence of female authors could be explained by linear and quadratic time effects. The quadratic effect was also significant $(t=3.78, p<0.001)$, indicating that the presence of female authors of tourism social science research has accelerated over time. The same steps 
were used to assess growth of male authors over time. The linear term resulted in a significant model $(F=28.99, p<0.001)$ which could explained $55 \%$ of the presence of male authors and in which time effect was significant $(t=5.38, p<0.001)$. The result of model estimation using both linear and quadratic effect was also significant $(F=15.28, p<0.001)$. However, the quadratic effect was insignificant $(t=1.12, p>0.005)$, indicating that presence of male authors in ATR has not accelerated over time.

In terms of the types of articles published in the journal, the majority of articles were qualitative (40.05). The proportion of qualitative articles increased dramatically from $3.23 \%$ in 1990 to $45.28 \%$ in 2015. During the same time period, the proportion of articles using quantitative approaches declined from $61.90 \%$ to $39.62 \%$. To assess growth in the four different types of articles published, a multiple regression analysis was used. The number of quantitative research articles published was regressed on the number of male and female authors and time as measured by year of publication. The regression model was statistically insignificant $(F=1.60, p>0.05)$. Insignificant results for mixed method articles $(F=1.16, p$ $>0.05)$ and for conceptual articles $(F=1.50, p>0.05)$ were also obtained. These findings suggested that time and presence of male and female authors could not explain changes in the number of quantitative, mixed-method, and conceptual articles published in the journal. The same statistical procedure was followed to analyze growth in qualitative articles. In this case, the regression model was statistically significant $(F=29.70, p<0.001)$ and explained $80 \%$ $\left(R^{2}=.802\right)$ of variance in the number of qualitative articles published in the journal. While time $(\beta=.07, t=.37, p>0.05)$ and presence of male authors $(\beta=.32, t=1.82, p>0.05)$ could not explained the growth of qualitative research, presence of female authors was positively associated with the number of qualitative research published in the journal $(\beta=.54$, $t=2.25, p<0.05)$. 
The results demonstrate that the increasing presence of female authors is positively associated with the number of published articles based on qualitative methodologies. Assuming that the proportion of successful submissions by women in relation to the overall number of submissions has remained constant, this suggests that women have a preference for such approaches over other research methods, at least with respect to submissions to ATR. One reason for this preference could be that women are more interested in qualitatively oriented critical scholarship that examines the views of marginalized social groups and other neglected domains of social life (Berdychevsky \& Gibson, 2015; Bianchi, 2009). It has also been suggested that women prefer research methodologies such as qualitative approaches, which capture human diversity, create positive change, and allow multiple worldviews and cultural differences to be captured (Swain, 2016). The affinity women have for critical scholarship and associated qualitative research methods may also rest on the embodied characteristics that are stereotypically associated with women such as their shared ethics of social justice, equality, diversity, and egalitarian thinking (Swain, 2016).

Likewise, shifts in authorship by gender post 2009 may reflect ATR having become a more attractive outlet for qualitative research given that the journal has "departed from the quantitative-deductive approaches and moved towards [a] qualitative-inductive tradition” (Xiao et al., 2013, p. 18), with the proportion of authorship reaching a stage that better reflects the gender ratio of tourism scholars overall (Hall, 2016; Munar et al., 2015). In focusing specifically on tourism gender research, Figueroa-Domecq et al. (2015) found that only $12 \%$ of papers published in ATR dealt with gender and that overall, a quantitative approach predominated. It is therefore clear, when combined with the results of the present study, that women's research interests in tourism go well beyond a specific focus on gender research. 
To conclude, although there is a clear dominance of male authorship in articles published in ATR in the time period examined, the findings are encouraging for those in the academic community that have drawn attention to gender bias in tourism knowledge production (Figueroa-Domecq et al., 2015; Munar et al., 2015). We note here not only the growth of female authors, but also acceleration over time. It is hoped that this continues in the future so as to bring a gender balance in tourism knowledge production. However, implicit within this may also be greater acceptance of the validity and value of qualitative research methods in the tourism field. Of course, further data on authorship patterns and methodological approaches from other tourism journals are needed to validate the findings, while qualitative engagement with article submitters, reviewers and editorial boards will also shed further insights. There may also be scope in investigating whether biosocial processes influence men and women choice of research methods. 


\section{REFERENCES}

Berdychevsky, L., \& Gibson, H. J. (2015). Phenomenology of young women's sexual risktaking in tourism. Tourism Management, 46, 299-310.

Bianchi, R. V. (2009). The 'critical turn'in tourism studies: A radical critique. Tourism Geographies, 11(4), 484-504.

Figueroa-Domecq, C., Pritchard, A., Segovia-Pérez, M., Morgan, N., \& Villacé-Molinero, T. (2015). Tourism gender research: A critical accounting. Annals of Tourism Research, 52, 87-103.

Hall, C. M. (2011). Publish and perish? Bibliometric analysis, journal ranking and the assessment of research quality in tourism. Tourism Management, 32(1), 16-27.

Hall, C. M. (2016). Publishing patterns of highly cited scholars in tourism and hospitality. Journal of Hospitality and Tourism, 14(1), 1-17.

Hunt, C. A., Gao, J., \& Xue, L. (2014). A visual analysis of trends in the titles and keywords of top-ranked tourism journals. Current Issues in Tourism, 17(10), 849-855.

Justham, D., \& Timmons, S. (2005). An evaluation of using a web-based statistics test to teach statistics to post-registration nursing students. Nurse Education Today, 25(2), 156163.

Li, J. \& Xu, Y. (2014). Author analyses of tourism research in the past thirty years-Based on ATR, JTR and TM. Tourism Management Perspectives, 13, 1-6.

Munar, A. M., Biran, A., Budeanu, A., Caton, K., Chambers, D., Dredge, D., Gyimothy, S., Jamal, T., Larson, M., Lindström, K. Nygaard, L., \& Ram, Y. (2015). The gender gap in the tourism academy: Statistics and indicators of gender equality. Copenhagen: While Waiting for the Dawn.

Oakley, A. (2000). Experiments in knowing: Gender and methods in the social sciences. Cambridge: Polity Press. 
Rosser, S. V. (Ed.). (2008). Women, science, and myth: Gender beliefs from antiquity to the present. Santa Barbara CA: Abc-Clio.

Swain, M. B. (2016). Embodying cosmopolitan paradigms in tourism research. In A. M. Munar \& T. Jamal (Eds.) Tourism research paradigms: Critical and emergent knowledges (pp. 87-111). Emerald Group Publishing Limited.

Xiao, H., Jafari, J., Cloke, P., \& Tribe, J. (2013). Annals: 40-40 vision. Annals of tourism research, 40, 352-385.

Zhao, W., \& Ritchie, J. B. (2007). An investigation of academic leadership in tourism research: 1985-2004. Tourism Management, 28(2), 476-490. 
Table 1. Trends in authorship and methodological approaches used (1990-2015).

\begin{tabular}{llll|lllll}
\hline Year & Male & Female & $\begin{array}{l}\text { Total } \\
\text { authors }\end{array}$ & Qual. & Quant. & Mixed & Conceptual & $\begin{array}{l}\text { Total } \\
\text { articles }\end{array}$ \\
\hline 1990 & $38(80.85)$ & $9(19.15)$ & 47 & $1(3.23)$ & $13(61.90)$ & $2(6.45)$ & $15(48.39)$ & 31 \\
1991 & $42(79.25)$ & $11(20.75)$ & 53 & $6(19.35)$ & $9(29.03)$ & $1(3.23)$ & $15(48.39)$ & 31 \\
1992 & $40(86.96)$ & $6(13.04)$ & 46 & $9(29.03)$ & $13(49.94)$ & $0(0)$ & $9(29.03)$ & 31 \\
1993 & $41(70.69)$ & $17(29.31)$ & 58 & $5(12.50)$ & $13(32.50)$ & $1(2.5)$ & $21(52.50)$ & 40 \\
1994 & $51(73.91)$ & $18(26.09)$ & 69 & $9(23.08)$ & $16(41.03)$ & $1(2.56)$ & $13(33.33)$ & 39 \\
1995 & $42(61.76)$ & $26(38.24)$ & 68 & $21(45.65)$ & $14(30.43)$ & $2(4.35)$ & $9(19.57)$ & 46 \\
1996 & $56(74.67)$ & $19(25.33)$ & 75 & $22(52.38)$ & $14(33.33)$ & $2(4.76)$ & $4(9.52)$ & 42 \\
1997 & $39(78)$ & $11(22)$ & 50 & $13(40.63)$ & $14(43.75)$ & $0(0)$ & $5(15.62)$ & 32 \\
1998 & $44(74.58)$ & $15(25.42)$ & 59 & $18(48.65)$ & $14(37.84)$ & $0(0)$ & $5(13.51)$ & 37 \\
1999 & $38(66.67)$ & $19(33.33)$ & 57 & $15(38.46)$ & $10(25.64)$ & $6(15.38)$ & $8(20.51)$ & 39 \\
2000 & $54(70.13)$ & $23(29.87)$ & 77 & $18(40)$ & $18(40)$ & $5(11.11)$ & $4(8.89)$ & 45 \\
2001 & $53(67.95)$ & $25(32.05)$ & 78 & $23(51.11)$ & $17(37.78)$ & $3(6.67)$ & $2(4.44)$ & 45 \\
2002 & $56(71.79)$ & $22(28.21)$ & 78 & $19(38)$ & $18(36)$ & $2(4)$ & $11(22)$ & 50 \\
2003 & $51(67.11)$ & $25(32.89)$ & 76 & $9(20.93)$ & $21(48.84)$ & $2(4.65)$ & $11(25.58)$ & 43 \\
2004 & $62(68.13)$ & $29(31.87)$ & 91 & $18(37.50)$ & $13(27.08)$ & $2(4.17)$ & $15(31.25)$ & 48 \\
2005 & $71(73.20)$ & $26(26.80)$ & 97 & $15(30)$ & $19(38)$ & $3(6)$ & $13(26)$ & 50 \\
2006 & $58(61.70)$ & $36(38.30)$ & 94 & $18(36)$ & $16(32)$ & $0(0)$ & $16(32)$ & 50 \\
2007 & $63(66.32)$ & $32(33.68)$ & 95 & $20(40.81)$ & $17(34.69)$ & $1(2.04)$ & $11(22.45)$ & 49 \\
2008 & $74(71.15)$ & $30(28.85)$ & 104 & $24(50)$ & $13(27.08)$ & $2(4.17)$ & $9(18.75)$ & 48 \\
2009 & $33(55.93)$ & $26(44.08)$ & 59 & $13(44.83)$ & $9(31.03)$ & $1(3.45)$ & $6(20.69)$ & 29 \\
2010 & $69(64.49)$ & $38(35.51)$ & 107 & $23(44.23)$ & $8(15.38)$ & $3(5.77)$ & $18(34.62)$ & 52 \\
2011 & $68(53.97)$ & $58(46.03)$ & 126 & $31(49.21)$ & $13(20.64)$ & $6(9.52)$ & $13(20.63)$ & 63 \\
2012 & $86(55.84)$ & $68(44.16)$ & 154 & $33(40.74)$ & $18(22.22)$ & $6(7.41)$ & $24(29.63)$ & 81 \\
2013 & $87(55.77)$ & $69(44.23)$ & 156 & $40(58.82)$ & $16(23.53)$ & $3(4.41)$ & $9(13.24)$ & 68 \\
2014 & $109(59.89)$ & $73(40.11)$ & 182 & $40(54.05)$ & $19(43.18)$ & $1(1.35)$ & $14(18.92)$ & 74 \\
2015 & $59(50.43)$ & $58(49.57)$ & 117 & $24(45.28)$ & $21(39.62)$ & $1(1.89)$ & $7(13.21)$ & 53 \\
\hline Total & $1484(65.32)$ & $788(34.68)$ & 2272 & $487(40.05)$ & $386(31.74)$ & $56(4.61)$ & $287(23.60)$ & 1216 \\
\hline
\end{tabular}

-Figures in bracket indicate percentages 


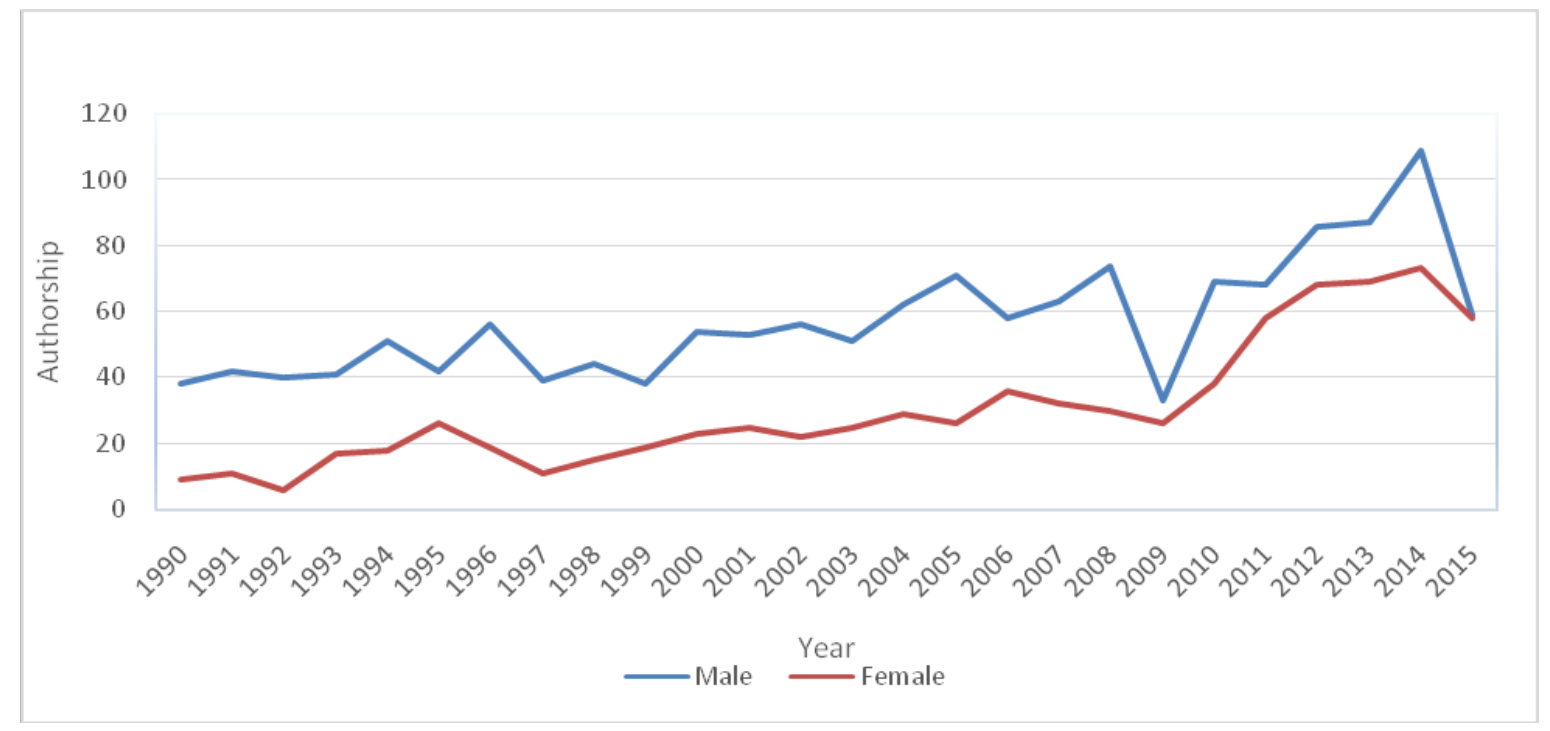

Figure 1. Time series of authorship by gender (1990-2015) 


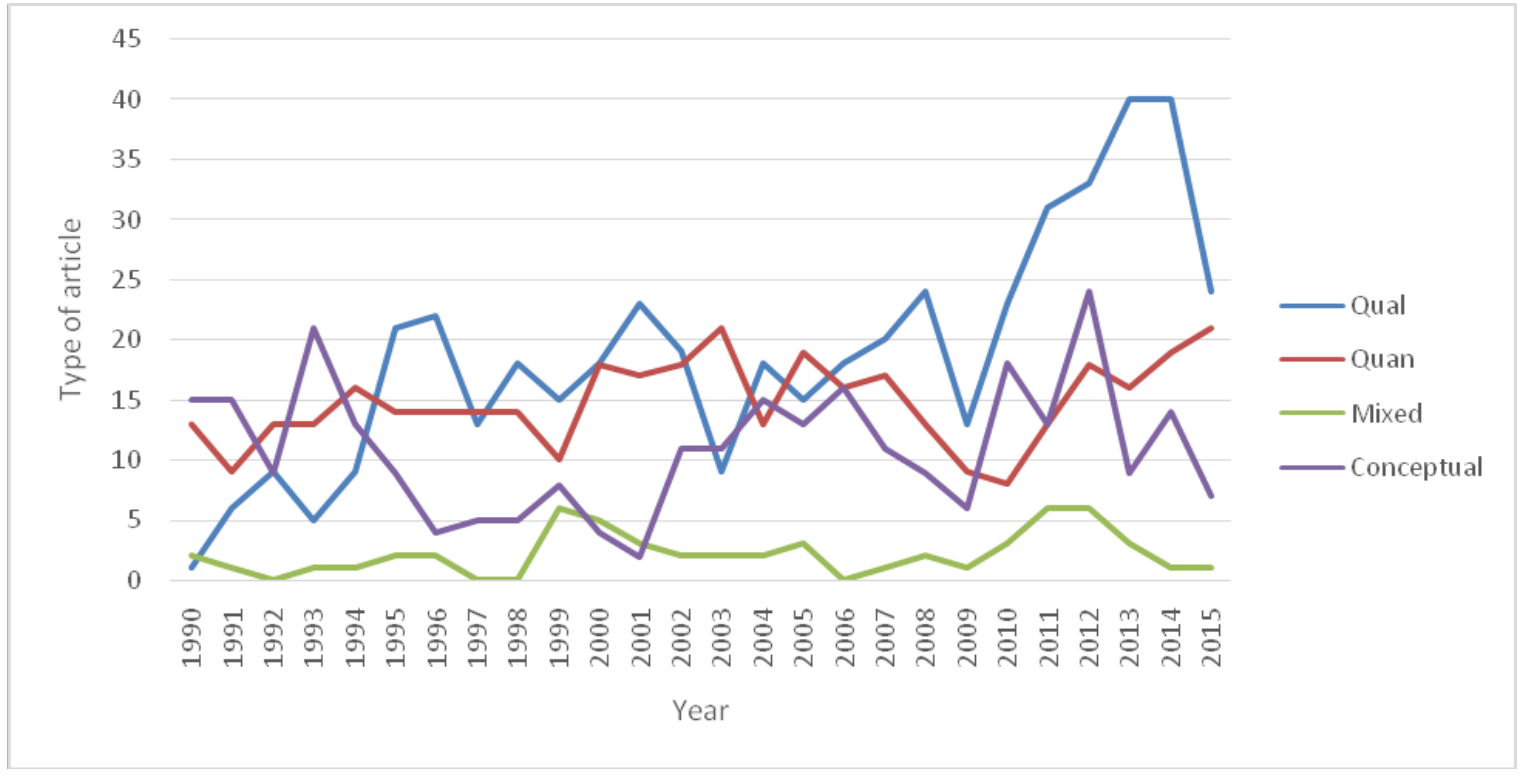

Figure 2. Time series of types of articles by methodological approaches (1990-2015) 